\title{
Corrigendum
}

\section{Corrigendum to "Current State of Off-Site Manufacturing in Australian and Chinese Residential Construction"}

\author{
Malik M. A. Khalfan and Tayyab Maqsood \\ School of Property, Construction and Project Management, RMIT University, Melbourne, VIC 3000, Australia \\ Correspondence should be addressed to Malik M. A. Khalfan; malik.khalfan@rmit.edu.au \\ Received 5 June 2016; Accepted 19 June 2016 \\ Copyright (C) 2016 M. M. A. Khalfan and T. Maqsood. This is an open access article distributed under the Creative Commons \\ Attribution License, which permits unrestricted use, distribution, and reproduction in any medium, provided the original work is \\ properly cited.
}

In the article titled "Current State of Off-Site Manufacturing in Australian and Chinese Residential Construction" [1], the following section should be added as acknowledgments.

\section{Acknowledgments}

This research was based on the research report titled "Industrialised Building in the Housing Sector-Current State in Australia," (ISBN 97809925377 15), and funded by the Department of Industry, Australia China Science and Research Fund. Also, the authors wish to acknowledge the contributions from the lead Chief Investigator (Professor Kerry London) and the Research Assistant (Mr. Peng Zhang) to the study.

\section{References}

[1] M. M. A. Khalfan and T. Maqsood, "Current state of off-site manufacturing in Australian and Chinese residential construction," Journal of Construction Engineering, vol. 2014, Article ID 164863, 5 pages, 2014. 


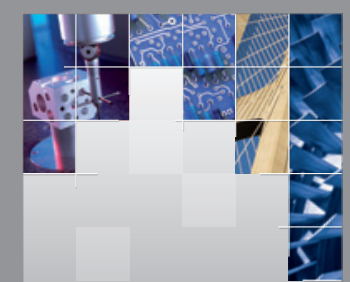

\section{Enfincering}
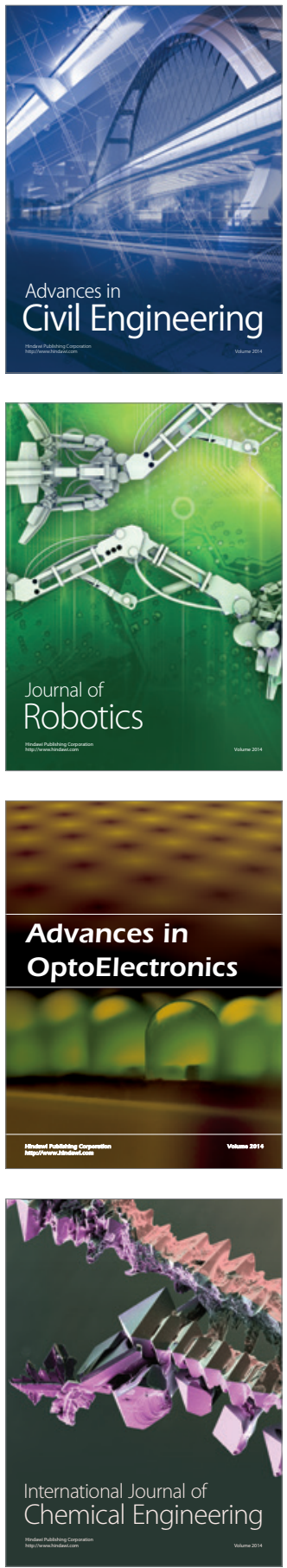

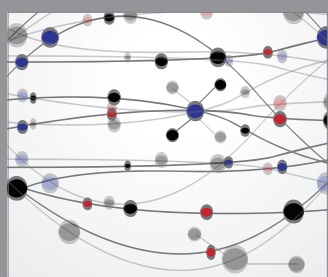

The Scientific World Journal

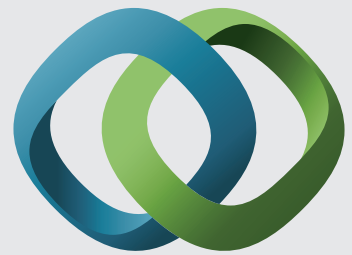

\section{Hindawi}

Submit your manuscripts at

http://www.hindawi.com
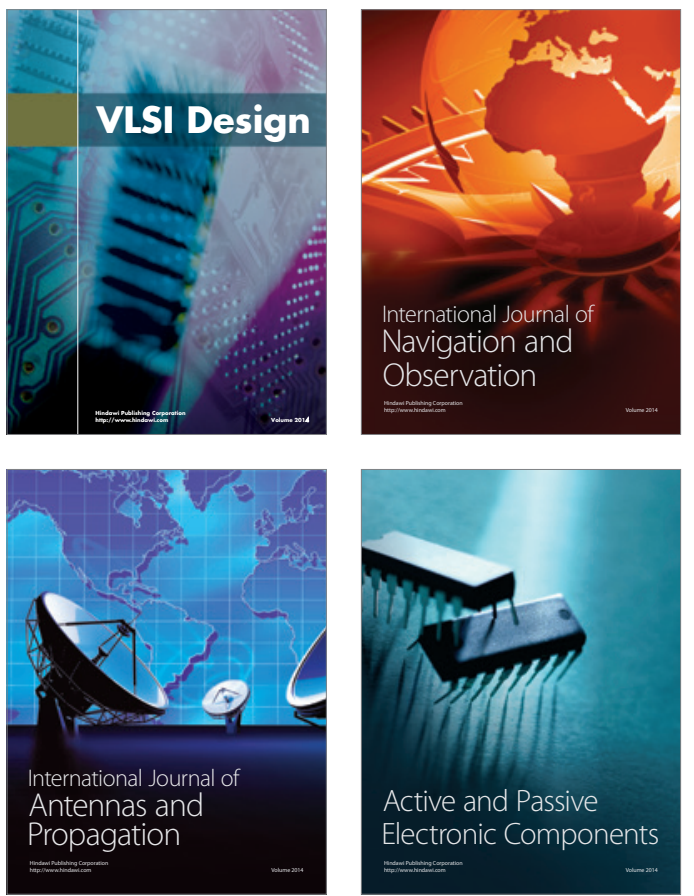
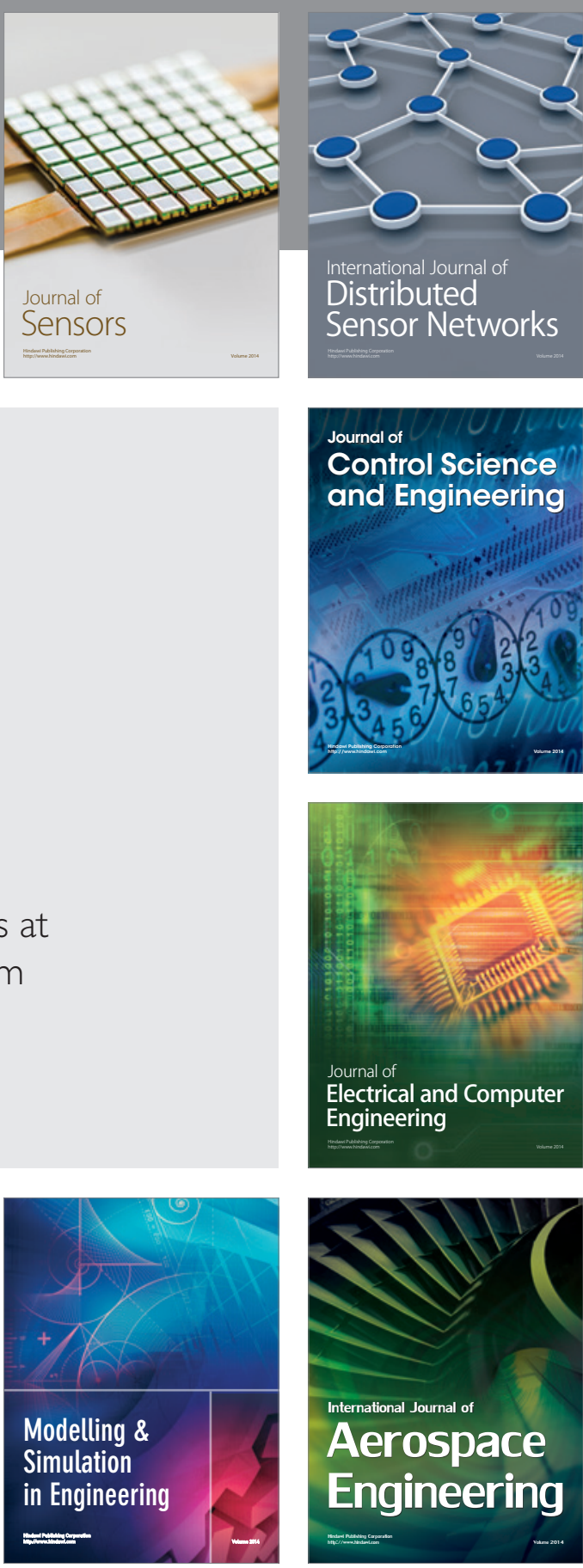

International Journal of

Distributed

Sensor Networks

Journal of

Control Science

and Engineering
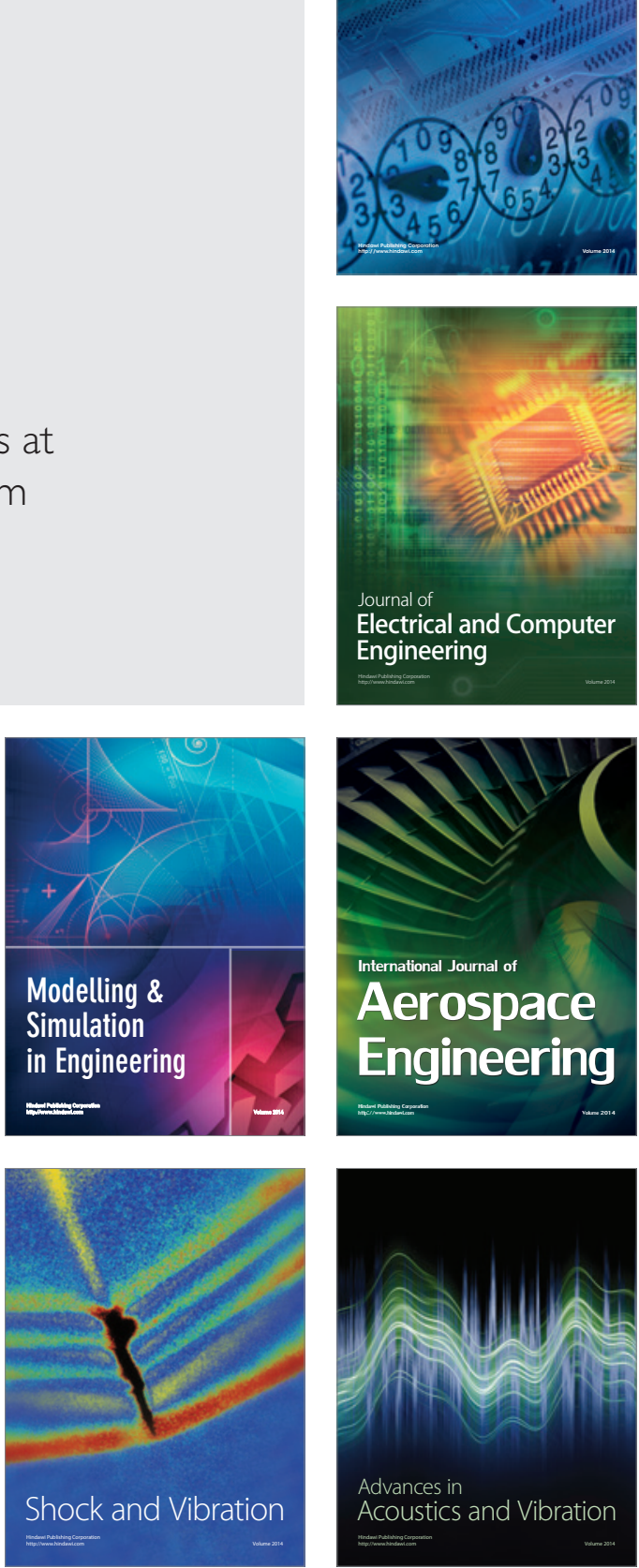